\title{
La metacognición en la profesionalización docente: el pensamiento crítico en un entorno mixto
}

\section{Metacognition in Teacher Professionalization: Critical Thinking in a Mixed Environment}

\author{
Adriana Margarita Pacheco-Cortés \\ Universidad de Guadalajara, Guadalajara (México) \\ adrianapacheco.c2015@gmail.com \\ Elba Patricia Alatorre-Rojo \\ Universidad de Guadalajara, Guadalajara (México) \\ patty.alatorre@gmail.com
}

\begin{abstract}
Resumen
Se presenta parte de una investigación realizada en torno a la metacognición, en específico de las características del pensamiento crítico evidenciadas en un texto presentado como reflexión, al término de un curso-taller de formación docente. Se plantea como pregunta de investigación ¿Qué características del pensamiento crítico propuestos por Marzano y Pickering (2005) se identifican en la redacción de una reflexión escrita sobre el aprendizaje logrado en un taller del PROFACAD y su aplicación en la práctica docente de los participantes?

El diseño de la investigación fue descriptivo con enfoque mixto. El método fue Análisis de contenido. Se presentan los concentrados de frecuencia de las características del pensamiento crítico. Como resultados se obtuvo que la característica de mayor frecuencia fue: la de Ser preciso y buscar precisión y la de menor fue: Responde de una manera apropiada a los sentimientos y al nivel de conocimientos de los demás. Se plantean como limitantes el tamaño de la muestra y el nivel diferente de habilidades de redacción de los docentes participantes.

Queda evidencia de la necesidad de capacitar al docente en la mejora consiente de las características del pensamiento crítico para que lo realice y pueda apoyar a sus estudiantes en su desarrollo.
\end{abstract}

Palabras clave

Formación de Profesores, Metacognición, Pensamiento Crítico, Sociedad del conocimiento.

\begin{abstract}
The present study is part of research over metacognition, particularly focused on features of critical thinking (Marzano and Pickering, 2005) by textual reflection after teacher-training. It is intended to respond the question: What characteristics of critical thinking are identified by writing reflection about learning achieved by attending a concrete in-service workshop, and its implementation in the instructional practice of the participants? Research design is descriptive, with a mixed approach. Method is content analysis. Frequency-concentrates of critical thinking features are presented. Outputs indicate that the prevalent feature was to be accurate, then to search for precision and, to a lesser extent, reacting to feelings appropriately and to the knowledge level from others. Limitations were sample size and several writing-skills levels in the participants. It is needed to train instructors on conscious improvement of thinking skills features, so they can perform and to be able to support their students' development.
\end{abstract}

Key words

Teacher Training, Metacognition, Critical Thinking, Knowledge based society. 


\section{Introducción}

En la sociedad del conocimiento las universidades tienen un papel fundamental en la calidad de los aprendizajes ya que se considera un factor de cambio social debido a que no se centra solo en el desarrollo tecnológico. Por lo anterior, quienes se involucran en la actividad docente, tienen el reto de propiciar ese cambio social, no solo al actualizarse en áreas específicas de conocimiento, sino también, ante el surgimiento de cambios en las instituciones, lograr profesionalizar su desempeño frente a un grupo. Esta profesionalización implica una actualización pedagógico-didáctica, tecnológica, disciplinar y transdisciplinar.

Se presenta en este documento una investigación realizada en torno a los factores del pensamiento crítico y la metacognición en profesionistas inmersos en capacitación docente en la sociedad del conocimiento. El pensamiento crítico se considera un hábito mental dentro del proceso de metacognición. Marzano y Pickering (2005) ubicaron la metacognición como un conjunto de hábitos mentales productivos. El individuo demuestra, de manera consistente, la capacidad de utilizarlos para aprender en cualquier situación y entiende cuándo y por qué es necesario su uso.

Este documento presenta parte de una investigación en torno a la metacognición realizada por participantes de un curso de formación continua en el período intersemestral del 2016 en la Universidad de Guadalajara (UdeG). Solo se da cuenta del análisis realizado en torno al hábito mental del pensamiento crítico. Los docentes participantes crearon expresiones escritas sobre reflexiones metacognitivas en las que analizaron y evaluaron razonamientos e interpretaron su realidad.

La investigación se realizó con docentes del Centro Universitario de la Ciénega (CUCI) dentro de un curso de actualización docente realizado en el periodo intersemestral. La Red Universitaria de Jalisco de la UdeG está constituida por quince Centros Universitarios, seis son Centros Universitarios Temáticos y nueve son Centros Regionales. Además cuenta con dos sistemas, el Sistema de Universidad Virtual y el Sistema de Educación Media Superior.

A decir de Parga (2016) el CUCI ha sido la principal opción de educación superior para la Región Ciénega y parte de la Región Centro de Jalisco, así como municipios de la zona Ciénega en el Estado de Michoacán. Este Centro tiene tres sedes: Ocotlán, Atotonilco y La Barca, ofrece 15 programas educativos de pregrado y 5 de posgrado.

Parga (2016) informó que los profesores del CUCI tomaron cursos de actualización pedagógica y curricular, con el fin de fortalecer la función docente, esa actualización se incrementó al $60.7 \%$, la oferta de cursos de capacitación a los profesores. Durante el periodo de 2015-2016 se capacitaron 129 profesores a través del Programa de Formación, Actualización y Capacitación Docente (Programa de Formación, Actualización y Capacitación Docente, Universidad de Guadalajara).

En la presentación del PROFACAD se hace mención a las características de este programa y una de ellas marca el "Propiciar el pensamiento crítico y reflexivo a partir de los contenidos curriculares establecidos y el perfil de egreso que se busca lograr mediante procesos creativos en los estudiantes" (UdG, 2017 b).

La metacognición en la profesionalización docente: el pensamiento crítico en un entorno mixto. Adriana Margarita Pacheco-Cortés y Elba Patricia Alatorre-Rojo. 


\section{Marco Conceptual}

Marzano y Pickering (2005) propusieron marcos para el estudio de los hábitos mentales productivos. Estos hábitos los ubican como elementos de la metacognición y los clasifican en pensamiento crítico, creativo y autorregulado. Como marco para esta investigación se plantea la formación de profesores, principios de la metacognición, los hábitos mentales y el pensamiento crítico.

\subsection{Formación de profesores}

Quienes desempeñan el rol de docentes en una institución constituyen uno de los elementos básicos para el logro de la calidad educativa. Al reconocerse esta premisa que se ve reflejada en las políticas públicas sobre educación superior en México, se han desarrollado procesos de formación, actualización y desarrollo de la planta académica en las diversas instituciones que ofrecen este nivel educativo.

En las instituciones que ofrecen educación superior es común encontrar que sus docentes tienen un perfil derivado de su formación profesional, sin embargo, no necesariamente tienen formación dirigida a la docencia. Esta formación la brindan las mismas universidades a su personal por lo que cursos de capacitación y actualización disciplinar se ven complementados con cursos de formación pedagógica.

En la Universidad de Guadalajara se han desarrollado varias acciones de formación y actualización docente. La primera en sistematizar estas acciones fue el Programa Institucional de Capacitación y Actualización para la Superación Académica (PICASA) en 1999.

En esta universidad, el Consejo de Rectores en octubre de 2015, aprobó el Programa de Formación, Actualización y Capacitación Docente (PROFACAD) con el objetivo de actualizar al personal académico, como marco tiene las tendencias, exigencias y demandas que se plantean a la educación superior en el siglo XXI (PROFACAD, 2017a). Este programa se integra por cinco módulos. El primero se enfoca al desarrollo de habilidades didáctico pedagógicas; el segundo tiende a la actualización disciplinar y generación de conocimiento por área específica con tecnologías (PROFOCAD, 2017b).

Un tercer módulo pretende habilitar al docente en temas de actualidad, como lo es la gestión de la información. El cuarto es de cultura general universitaria, su propósito es reconstruir la identidad y el sentido universitario. Finalmente, el quinto módulo se enfoca a la capacitación en las nuevas tendencias de generación, producción científica y transferencia tecnológica, entre otras (PROFOCAD, 2017b).

\subsection{Metacognición}

Flavell (1976) señaló que la metacognición es un conocimiento que una persona tiene sobre sus propios procesos y productos cognitivos o cualquier información relacionada a ellos, pensar sobre sus procesos de aprendizaje o de pensamiento. Para Säälik (2016) el concepto de metacognición es difícil de comprender debido a su complejidad, y la interconexión con otros conceptos. Para Lai (2011) la evaluación de la metacognición es un reto por varias razones: (1) la metacognición es un constructo complejo, que implica una serie de diferentes tipos de conocimientos y habilidades; (2) no es observable de manera directa; (3) en la práctica se confunde, tanto con la capacidad verbal como con 
la capacidad de memoria de trabajo; y (4) las medidas existentes tienden a ser estrechas en el enfoque y descontextualizadas del aprendizaje en la escuela.

Marzano y Pickering (2005) ubicaron la metacognición como hábitos mentales productivos, declararon que los estudiantes demuestran, de manera consistente, la capacidad de utilizarlos para aprender en cualquier situación y que entienden cuándo y por qué es necesario utilizar hábitos específicos. Estos autores categorizaron esos hábitos mentales como: pensamiento crítico, pensamiento creativo y pensamiento autorregulado.

La conciencia metacognitiva de acuerdo con Säälik (2016) establece una mediación entre todas las formas conocidas de aprendizaje para seleccionar una de ellas, identificar cuál de ellas es la más útil y hacer un cambio si es necesario. A decir de esta autora, algunas estrategias de aprendizaje se denominan estrategias metacognitivas si contribuyen a niveles altos de conciencia, si promueven la comprensión, si incluyen atributos de monitoreo o si se derivan de cualquiera de los componentes antes mencionados de la metacognición.

\subsection{Hábitos mentales}

El hábito mental se puede definir como un comportamiento adquirido, repetido, es decir habilidades que se van adquiriendo de forma gradual en un proceso de aprendizaje hasta llegar a lograr patrones de comportamiento que se repiten casi inconscientemente.

A decir de Ponce (2002), Costa y Kallick plantearon 16 hábitos de la mente y los describen como:

1. Ser persistente. Terminar las tareas o problemas y mantenerse concentrado.

2. Manejar la impulsividad. Tomarse su tiempo, pensar antes de actuar, permanecer calmado pensativo y deliberar.

3. Escuchar con comprensión y empatía. Buscar entender a los otros. Dedicar energía mental a las ideas y pensamientos de los otros. Mantener nuestros propios pensamientos pero percibir el punto de vista y las emociones del otro.

4. Pensar flexiblemente. Intentar ver la situación desde una forma distinta, cambiar de perspectivas, generar alternativas y considerar opciones.

5. Pensar sobre el pensamiento. Conocer sobre tu forma de conocer, estar alerta ante los pensamientos propios, las estrategias, y las acciones propias, y cómo afectan a otros. 6. Buscar la exactitud. Verificar una y otra vez nuestro trabajo, fomentar el deseo por la exactitud y la fidelidad.

6. Preguntar y proponer problemas. ¿Cómo conozco? Desarrollar una actitud de cuestionamiento. Considerar la información que necesitamos, elegir las estrategias que producen la información y encontrar problemas para resolver.

7. Aplicar el conocimiento pasado a nuevas situaciones. Usar lo que sabemos. Utilizar nuestro conocimiento y transferirlo a través de situaciones en que hemos aprendido.

8. Pensar y comunicarse con claridad y precisión. Ser claro. Buscar la comunicación exacta tanto en forma escrita como oral. Evitar las generalizaciones extremas, las distorsiones y las omisiones.

9. Reunir información a través de todos los sentidos. Utilizar nuestras formas naturales de recopilación de información a través de los sentidos. 
10. Crear, imaginar e innovar. Intentar formas diferentes de acción, generar nuevas ideas, buscar la fluidez y la originalidad.

11. Responder con asombro y admiración ante nuestro entorno. Permitirse maravillarse ante los fenómenos naturales y la belleza que nos rodea.

12. Tomar riesgos de manera responsable. Experimentar el límite de nuestra propia competencia.

13. Encontrar el humor. Sonreír. Buscar la incongruencia en la vida. Reírse de uno mismo, cuando se pueda.

14. Pensar de forma interdependiente. Trabajar con otros. Trabajar y aprender de los otros en situaciones recíprocas.

15. Permanecer abierto al aprendizaje continuo. Aprender de las experiencias. Estar orgulloso y ser humilde para admitir lo que no sabemos. Resistir las complacencias. (Ponce (2002), pp.103-04).

Por su parte Marzano y Pickering (2005), en su modelo para definir el proceso de aprendizaje plantean 5 dimensiones y ubican los hábitos mentales productivos en la $5^{\text {a }}$ dimensión. En esta dimensión ubican el pensamiento crítico, el creativo y el autorregulado.

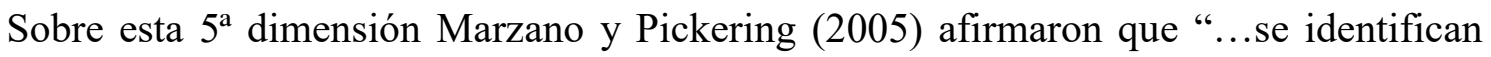
hábitos mentales productivos que, junto con las actitudes y percepciones, forman un telón de fondo para el proceso de aprendizaje." (p. 261). Estos autores plantearon que no se puede predecir con seguridad cuál conocimiento necesitarán los estudiantes, pero sí se puede predecir con un buen grado de confianza que en cada etapa de su vida necesitarán seguir aprendiendo y los hábitos mentales productivos los ayudarán a ser aprendedores exitosos. Para lograr esto se les debe apoyar para que demuestren su capacidad para utilizar los hábitos mentales productivos de forma consciente.

En la investigación que se presenta en este documento se hace una relación de los hábitos mentales planteados por Costa y Kallick en Ponce (2002) y las características que plantean Marzano y Pickering (2005) para el pensamiento crítico.

\subsection{Pensamiento crítico}

El pensamiento crítico a decir de Campos (2007) es consustancial a la naturaleza humana. Se desarrolla en cada individuo en grados diferentes pero todo ser humano cuenta con características de este tipo de pensamiento. Es a decir de este autor una habilidad consciente, sistemática y deliberada que utilizan los individuos para la toma de decisiones; es aplicable en toda la vida profesional y personal.

El pensamiento crítico se estudia como un proceso cognitivo de carácter racional, analítico y reflexivo, que cuestiona de forma sistemática la realidad y el mundo para llegar a la verdad. Es un proceso intelectual que opera al analizar y evaluar un asunto o circunstancia para una vez lograda la suficiente información y realizado una serie de razonamientos llegar a una conclusión o a una postura.

\subsection{Sociedad del conocimiento}

Para Krüger (2006) la sociedad del conocimiento no se centra en el desarrollo tecnológico sino que se considera como un factor del cambio social (entre otros factores), pone de ejemplo la expansión de la educación. Según este enfoque, el conocimiento será cada vez más, la base de los procesos sociales en diversos ámbitos 
funcionales de las sociedades. Este autor, señaló que la transformación actual de la sociedad indica un cambio de modo de producción social, dada la creciente importancia de la información o del conocimiento para los procesos socio-económicos.

Stehr (2000) señaló que los avances tecnológicos y científicos en la sociedad del conocimiento son una de las causas de la incertidumbre actual. Por ejemplo, los avances en las tecnologías de información y comunicación han propiciado el aumento de la creación, producción y distribución del conocimiento; con ello, las universidades han aumentado su flexibilidad para poder adaptarse a los cambios en la educación, ofrecen cursos masivos, en línea, abiertos y de participación ilimitada (MOOC por sus siglas en inglés). También, el aumento del conocimiento científico y su amplia difusión causan más incertidumbre, fragilidad y contingencia (Stehr, 1996). Krüger (2006) afirmó que el mayor conocimiento produce también más desconocimiento, que uno de los rasgos de la sociedad del conocimiento es el aumento de las zonas de incertidumbre, convirtiendo la ignorancia - entendida como el desconocimiento del no-conocimiento - en incertidumbre - entendido como el conocimiento del no-conocimiento (yo solo sé que no sé nada).

En esta investigación se retoma la definición de Säälik (2016) quien señaló que la metacognición comprende un concepto más amplio de conciencia del propio pensamiento, ciertos procesos de ejecución de las tareas de aprendizaje (estrategias), así como los procesos de evaluación de estos procesos, también, evaluar si el pensamiento y la elección de estrategias son suficientes para la tarea. De la propuesta de los hábitos mentales de Costa y Kallick se toman los coincidentes con el planteamiento de Marzano y Pickering (2005) sobre hábitos mentales productivos que corresponden al pensamiento crítico.

\section{El Problema}

En la Universidad de Guadalajara se tiene sistematizado el proceso de formación y actualización docente tanto para el nivel medio superior como para el nivel superior. Este proceso se realiza, como ya se ha mencionado en el llamado PROFACAD. Como parte de este programa, en el módulo de actualización disciplinar en el Centro Universitario de la Ciénega, se impartió en modalidad mixta (sesiones presenciales y trabajo en línea) el taller "Preparación de un paper/artículo para una revista", con una duración de 40 horas. El objetivo del taller fue generar el borrador de un artículo con un discurso académico para enviarlo a una revista, esto con la aplicación de las etapas de planeación, investigación y redacción de un texto. En el caso de este taller, la entrega del borrador fue en equipo de 3 integrantes.

A lo largo del desarrollo de este taller se hizo hincapié teóricamente, en actividades metacognitivas, sin embargo, no se dio la oportunidad de evidenciar o verificar que los participantes las realizaran. Para dar cuenta de procesos que evidenciaran un pensamiento crítico, como parte de un proceso metacognitivo en los docentes participantes, se solicitó una actividad final, que consistió en entregar un documento con un análisis sobre lo aprendido en este taller. Se pidió un escrito no mayor de una cuartilla, con una reflexión sobre los aprendizajes logrados en este taller y la descripción de cómo aplicarían dichos aprendizajes en su práctica docente cotidiana. Las reflexiones escritas de los docentes fueron los insumos/datos que se analizaron para realizar esta investigación. 
Al principio del taller, se solicitó una actividad individual a cada participante para recuperar los conocimientos previos sobre las etapas de la planeación del discurso académico con la siguiente pregunta generadora ¿Cuáles son las etapas de la planeación del discurso académico? en el diseño instruccional.

Los participantes ejecutaron la tarea con una estrategia para realizar esquemas sobre lo que ellos entendían acerca de estas etapas, se comentó que no importaba si estaban bien realizados porque se trataba de una actividad preliminar. Una vez que elaboraron esos esquemas, los intercambiaron con un compañero, de tal manera que no se quedaran con su propio esquema. Después, cada participante interpretó de manera oral lo que su compañero intentó esbozar en su diseño; los participantes que tenían más experiencia realizaron críticas constructivas a los productos (esquemas) de sus compañeros. Esta actividad de socialización y exhibición ayudó a los docentes participantes a analizar sus propios errores, con lo que se realizaba ya una actividad sin que se precisara su realización de forma consiente, característica de la metacognición.

Al final de las interpretaciones, se preguntó a los autores de los esquemas si lo que había interpretado su compañero de su esquema correspondía a lo que se tuvo en mente al realizarlo; de tal manera que, los participantes autoevaluaron sus procesos y su producto, identificaron los errores que cometieron y externaron lo que les faltó integrar. Sin embargo, consideramos que no evaluaron (a) su pensamiento crítico y (b) si la elección de estrategias fue suficiente para la tarea.

De lo anterior se derivó el problema que detonó la investigación que se presenta: el desconocimiento de las características del proceso metacognitivo en los participantes, docentes del CUCI. Esta evidencia se buscó en el escrito que presentaron esos docentes participantes de un taller de actualización docente.

\subsection{Pregunta de investigación}

¿Qué características del pensamiento crítico propuestos por Marzano y Pickering (2005) se identifican en la redacción de una reflexión escrita sobre el aprendizaje logrado de los participantes en un taller del PROFACAD y su aplicación en la práctica docente?

\section{Metodología}

La metodología representa el camino a seguir para abordar directamente el problema de investigación.

\subsection{Contexto y objetivos de la investigación}

Las reflexiones escritas por los docentes universitarios que se analizaron en esta investigación, las elaboraron los participantes del taller. Este taller pertenece al Programa de Formación, Actualización y Capacitación Docente enunciado en este artículo como PROFACAD corresponde al tercer módulo de dicho programa, éste pretende habilitar al docente en temas de actualidad, como lo es la gestión de la información para la producción académica. 
El objetivo de la investigación fue ubicar procesos metacognitivos en la ejecución de las actividades finales entregadas por los docentes de educación superior, participantes en un taller de actualización realizado en modalidad mixta.

El objetivo específico de esta parte de la investigación fue: identificar las características del pensamiento crítico propuestos por Marzano y Pickering (2005) en la redacción de una reflexión escrita sobre el aprendizaje logrado de los participantes en un taller del PROFACAD y su aplicación en la práctica docente.

\subsection{Instrumentos}

En la investigación realizada, para la parte descriptiva se utilizaron tablas de frecuencia y tablas de codificación. Las tablas de frecuencia concentraron las frecuencias de ideas a partir de la codificación que se realizó, de acuerdo a la propuesta de Marzano y Pickering (2005) para caracterizar el pensamiento crítico.

Se muestra en la tabla 1 la codificación que se diseñó para la caracterización del pensamiento crítico. En la tabla 2 la definición de las características de este tipo de pensamiento y en la tabla 3 el instrumento diseñado para concentrar las frecuencias de las características del pensamiento crítico ubicadas en los documentos analizados.

\section{Tabla 1}

Códigos para caracterizar el pensamiento crítico

\begin{tabular}{ll}
\hline Característica & Código \\
\hline Ser preciso y buscar precisión & PP \\
Ser claro y buscar claridad & CC \\
Mantener la mente abierta & MA \\
Contener los actos impulsivos & CAI \\
$\begin{array}{l}\text { Asumir una postura cuando la situación lo amerite } \\
\text { Responde de una manera apropiada a los }\end{array}$ & RA \\
$\begin{array}{l}\text { sentimientos y al nivel de conocimientos de los } \\
\text { demás }\end{array}$ & \\
\hline
\end{tabular}

Tabla 2

Definición de características del pensamiento crítico

\begin{tabular}{ll}
\hline Característica & Definición \\
\hline Ser preciso y buscar precisión. & Convertir la precisión en una meta \\
& utilizando varias técnicas para lograrla \\
& y reconocer que es responsabilidad del \\
& emisor y del receptor del mensaje fijar \\
& y esperar altos entandares de \\
precisión.
\end{tabular}

\begin{tabular}{ll}
\hline Ser claro y buscar claridad. & No utilizar términos ambiguos \\
& Verificar que se entiendan los \\
& términos que se utilizan en la \\
& comunicación. \\
\hline Mantener la mente abierta. & Escuchar, tomar en cuenta y tratar de \\
& entender diferentes perspectivas e \\
& ideas para optimizar la comunicación. \\
\hline Contener los actos impulsivos. & Retrasar una decisión o acción hasta \\
\hline
\end{tabular}

La metacognición en la profesionalización docente: el pensamiento crítico en un entorno mixto. Adriana Margarita Pacheco-Cortés y Elba Patricia Alatorre-Rojo. 


\begin{tabular}{lll}
\hline & & reunir la suficiente información. \\
\hline $\begin{array}{l}\text { Asumir una postura cuando la } \\
\text { situación lo amerite. }\end{array}$ & $\begin{array}{l}\text { Tomar postura una vez que se evaluó } \\
\text { la evidencia y se construyó una } \\
\text { fundamentación. }\end{array}$ \\
\hline $\begin{array}{l}\text { Responde de una manera apropiada } \\
\text { a los sentimientos y al nivel de }\end{array}$ & $\begin{array}{l}\text { Calcular lo que los demás sienten y } \\
\text { piensan para con esa base adaptar el } \\
\text { conocimientos de los demás. }\end{array}$ \\
\hline
\end{tabular}

Nota: Tomado de Marzano y Pickering, (2005,p.274-282)

\subsection{Método}

La investigación que se presenta fue de corte descriptivo con un enfoque mixto predominantemente cualitativo. Éste, a decir de Creswell (2003), implica múltiples formas de recolección y análisis de datos, tanto información cualitativa como cuantitativa. Se solicitó a los participantes del curso una reflexión escrita en torno a los aprendizajes logrados en el taller y cómo los aplicarían en su práctica docente. En esas reflexiones, se identificaron algunas características del pensamiento crítico en las reflexiones metacognitivas de los participantes de la investigación. La parte cualitativa se trabajó con análisis de contenido de los datos y la parte cuantitativa con estadística básica, al calcular las frecuencias de las características del pensamiento crítico y graficarlas.

Para el análisis cualitativo de las ideas plasmadas en los documentos con las reflexiones, buscando características del pensamiento crítico relacionadas a procesos metacognitivos, se utilizó como método el Análisis de Contenido. Gómez (1999) afirmó que éste es un método que busca descubrir el significado de los mensajes. Este autor plantea que se trata de un trabajo indirecto ya que no se tiene contacto con los individuos, se realiza a través de lo que estos producen ya sea en formatos escritos, orales o bien en audiovisuales o imágenes. Estos productos pueden haber sido construidos por un individuo o por un grupo y permiten deducciones tanto cualitativas como cuantitativas.

El análisis de contenido a decir de Carlós y Telmo (s.f.) es una técnica confiable y equilibrada mediante la cual se logra obtener significados de materiales desplegados en un soporte específico. El aspecto cuantitativo se da cuando se recurre a elementos clasificatorios o cuantificables y el cualitativo cuando se requiere buscar detalles relativos al contenido y aplicar variables e indicadores que pongan en evidencia un contenido latente que lleven a una labor interpretativa.

Por otra parte, el análisis de contenido es planteado por Klaus Krippendorff como "...una técnica de investigación destinada a formular, a partir de ciertos datos, inferencias reproducibles y válidas que puedan aplicarse a su contexto." (Krippendorff, 1990, p. 28). El análisis de contenido, a decir de este autor, aun cuando tenga finalidades solo descriptivas no debe dejar de lado las consideraciones relacionadas con su validez y tiene que estar vinculado con el contexto en que se realiza. En este tipo de análisis debe quedar claro qué datos se analizan, cómo se definen y de qué población se extraen. Asimismo, debe enunciarse con claridad la finalidad u objetivo de las inferencias.

El análisis de contenido es un método observacional que registra los comportamientos reales de los informantes, lo que permitió considerar los comportamientos no verbales 
ya que se habían realizado también sesiones presenciales y se conocía la forma de expresarse de los docentes participantes. Whitebread et al. (2009) declararon que en la evaluación de la metacognición, los métodos observacionales tienen ventajas sobre los métodos de auto-reporte y de pensamiento en voz alta.

En la investigación que se presenta se utilizó el análisis de contendido propuesto por Krippendorff (1990) aplicándolo a las ideas plasmadas en el documento solicitado al finalizar el taller dentro de PROFACAD. Los datos o unidades de análisis fueron frases dentro de los párrafos del documento. Se utilizaron las categorías e indicadores planteados por Marzano y Pickering (2005).

El análisis realizado en esta investigación, se establece como de carácter interno en los escritos presentados por los docentes y que fueron publicados en la plataforma, procurando destacar su sentido. La crítica interna se centra en una interpretación personal y subjetiva, desde la intensión e intuición del investigador y para conseguirlo se deben seleccionar palabras o frases determinadas, estableciendo su frecuencia de aparición; lo que sirve de base para generar conclusiones (López, 2002).

\subsection{Participantes}

La planta docente de CUCI está constituida por 493 docentes, 159 son profesores de tiempo completo, 21 de medio tiempo y 284 de asignatura. Además, 29 técnicos académicos de tiempo completo y 1 de medio tiempo. Declaró que más del $80 \%$ de estos profesores cuenta con perfil PRODEP. La edad promedio es de 41 años, el grado académico promedio de los profesores de tiempo completo equivale a estudios de posgrado.

Los sujetos de investigación fueron docentes del Centro Universitario de la Ciénega que participaron en el taller "Preparación de un paper/artículo para una revista". Estos docentes se desempeñan en el nivel educativo de licenciatura, aunque algunos de ellos también lo hacen en educación media y otros en posgrado.

En el taller participaron 25 profesores, 11 varones y 14 mujeres. De estos, 22 enviaron su actividad final en el espacio de entrega de tareas en la plataforma Moodle. Uno de ellos envío otro documento que no correspondía a la actividad de reflexión por lo que solo se analizaron 21 documentos.

\section{Resultados}

\subsection{Características del pensamiento crítico}

Se recolectaron los datos explícitos e implícitos de las reflexiones que escribieron los profesores (actividad final) sobre el aprendizaje y su aplicación en la práctica docente cotidiana de los contenidos del curso-taller. Los datos explícitos se obtuvieron al ubicar las características del pensamiento crítico en frases claras. Los datos implícitos se ubicaron a criterio de los investigadores al interpretar frases confusas o incompletas que pudieran clasificarse en alguna característica del pensamiento en estudio. Estos datos fueron las características del pensamiento crítico propuestas por Marzano y Pickering (2005): (a) ser preciso y buscar la precisión, (b) ser claro y buscar la claridad, (c) mantener la mente abierta, (d) contener la impulsividad, (e) asumir una postura y (f) responder de manera apropiada. 
De acuerdo al planteamiento de la pregunta específica de investigación se ubicaron las frecuencias de cada una de las características del pensamiento crítico. En la tabla 4 se presenta el concentrado de resultados.

Tabla 4

Concentrado de frecuencias de características del pensamiento crítico.

\begin{tabular}{lllllll}
\hline Informante & PP & CC & MA & CAI & AP & RA \\
\hline 1 & 11 & 13 & 5 & 7 & 3 & 5 \\
2 & 5 & 5 & 3 & 4 & 9 & 1 \\
3 & 13 & 12 & 5 & 9 & 8 & 4 \\
4 & 14 & 14 & 10 & 10 & 11 & 6 \\
5 & 7 & 7 & 7 & 4 & 6 & 7 \\
6 & 18 & 16 & 9 & 10 & 8 & 5 \\
7 & 8 & 8 & 4 & 8 & 6 & 4 \\
8 & 7 & 7 & 5 & 7 & 7 & 4 \\
9 & 14 & 14 & 8 & 9 & 10 & 8 \\
10 & 6 & 6 & 4 & 5 & 6 & 4 \\
11 & 9 & 9 & 3 & 3 & 4 & 1 \\
12 & 9 & 9 & 4 & 8 & 4 & 1 \\
13 & 15 & 11 & 10 & 13 & 10 & 6 \\
14 & 13 & 12 & 6 & 6 & 5 & 3 \\
15 & 6 & 6 & 3 & 6 & 7 & 2 \\
16 & 11 & 10 & 8 & 8 & 10 & 7 \\
17 & 7 & 7 & 7 & 6 & 6 & 2 \\
18 & 21 & 16 & 7 & 13 & 4 & 7 \\
19 & 7 & 5 & 4 & 3 & 7 & 1 \\
20 & 15 & 15 & 9 & 9 & 8 & 8 \\
21 & 11 & 10 & 3 & 3 & 3 & 2 \\
\hline
\end{tabular}

Nota: Elaboración de las autoras.

En la figura 1 se observa que el informante 18 (I18) fue quien logró ser preciso y buscar la precisión 21 veces en su reflexión; en contraste con el informante 2 (I2), quien solo alcanzó ser preciso en su reflexión en 5 ocasiones. Se presentan algunos ejemplos de precisión de los informantes 4 (I4) y 19 (I19).

"Las partes mínimas que debe de contener un artículo científico son: título, resumen, introducción, método, resultados, discusión, conclusiones, referencias y apéndices" $(I 19,2017)$. Esta reflexión es precisa porque escribe de manera específica las partes mínimas a incluir en un artículo científico, similar a dar instrucciones precisas. También, los informantes 3, 6, 8, 9, 12, 13, 16 y 19 incluyeron la estructura/etapas/procesos de un artículo. "un proyecto de investigación no es solamente un proceso de construcción de conocimiento; es también un proceso de construcción de un equipo encargado de llevarlo a buen término” (I1, 2017).

Los comentarios anteriores de los informantes 1 (I1) y 4 (I4) son precisos porque son específicos, en las siguientes partes de los escritos "el proceso de construcción de conocimiento" y "el curso-taller totalmente funcional y aplicable" determinan a ejecutar algo y se perciben de forma clara. La figura 1 muestra el concentrado de frecuencias de la característica "ser preciso y buscar la precisión". 


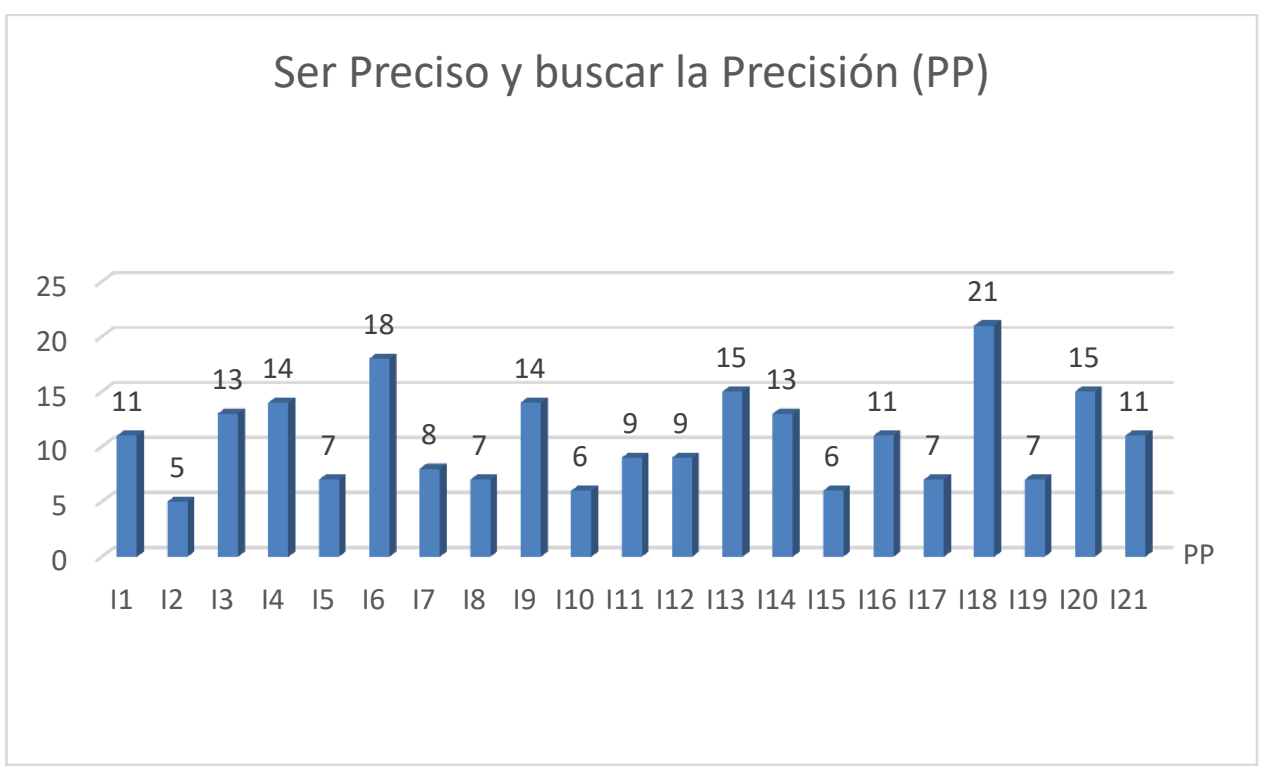

Figura 1. Frecuencia del hábito mental productivo de precisión.

En la figura 2 se observa que los informantes 6 y 18 fueron quienes lograron ser claros y buscar la claridad, presentan 16 ideas con esta característica en la reflexión de cada uno; en contraste con los informantes 2 y 9 quienes evidencian ser claros en su reflexión en 5 ocasiones (ver figura 2). Se presentan algunos ejemplos de esta característica de los informantes 1 y 4 .

"un taller que hace reflexionar la importancia en el escribir de una investigación". "una pregunta en la mente ¿Cuáles fueron las contribuciones de todo este conjunto de prácticas y procesos a la formación investigativa de los profesores participantes?” (I1, 2017). Otro ejemplo, "La instructora nos explicó la metodología adecuada para poder trabajar una idea de investigación y cómo desarrollarla de manera correcta para poder publicar en revistas de calidad" (I4, 2017).

Los comentarios expresados por los informantes 1 y 4 son claros porque la comunicación es nítida, escriben lo que desean decir, la información que presentan es concisa, no es confusa y es directa. La figura 2 presenta el concentrado de frecuencias de características de claridad. Donde se observa que los informantes 6 y 18 escriben con más claridad. 


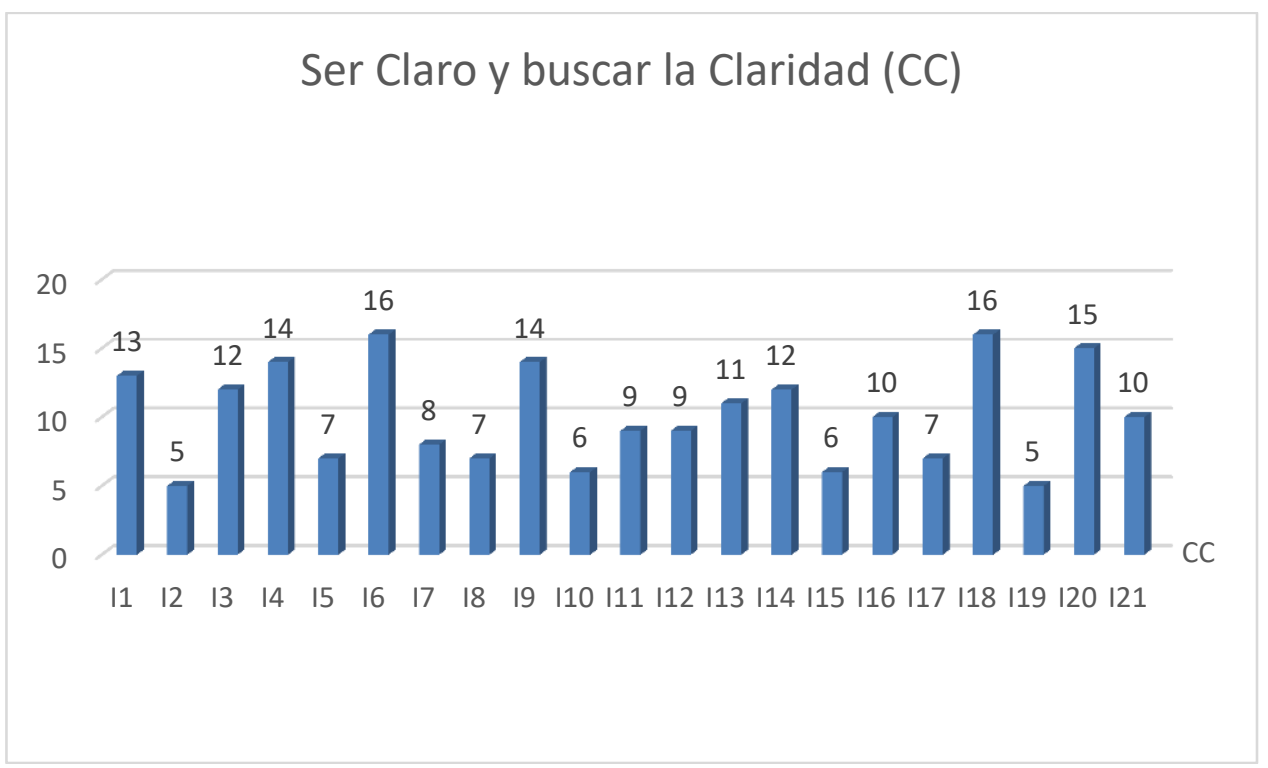

Figura 2. Frecuencia del hábito mental productivo de claridad.

En la figura 3 se observa que los informantes 4 y 13 fueron quienes lograron mantener la mente abierta, se ubican 10 ideas en su reflexión con esta característica; en contraste con el informante 2, quien mantuvo la mente abierta en su reflexión solo en 3 ocasiones. Se presentan algunos ejemplos de esta característica de los informantes 1 y 4.

"aprendi de mis compañeros del curso ya que aportaron ideas y experiencias que enriquecieron mi conocimiento en torno a las vicisitudes a las que nos enfrentamos todo el tiempo los que realizamos investigación y queremos publicar correctamente y con calidad" (I1, 2017). Otro ejemplo, "En lo particular aprendí técnicas sencillas pero muy importantes para el desarrollo de una idea de investigación, particularmente la técnica de la estrella... me pareció muy práctica y el hecho de realizarla en el propio taller me permitió darme cuenta de otras formas de desarrollar un trabajo de investigación para su posterior publicación” (I4, 2017).

En los comentarios expresados por los informantes 1 y 4 se observa que tienen una mente abierta porque socializaron e interaccionaron son sus compañeros el I1 externo que aprendió de sus compañeros y el I4 aprendió la técnica de la estrella, en el diseño instruccional fue una actividad realizada en equipo, en las siguientes partes de los escritos de los mismos informantes "aportan ideas y experiencias que enriquecieron mi conocimiento" y "el hecho de realizarla en el propio taller me permitió darme cuenta de otras formas" se observa que los informantes escucharon perspectivas e ideas diferentes con el fin de mantener una mente abierta para entenderlas. La figura 3 muestra el concentrado de frecuencias de la característica Mente abierta. 


\section{Mantener la Mente Abierta (MA)}

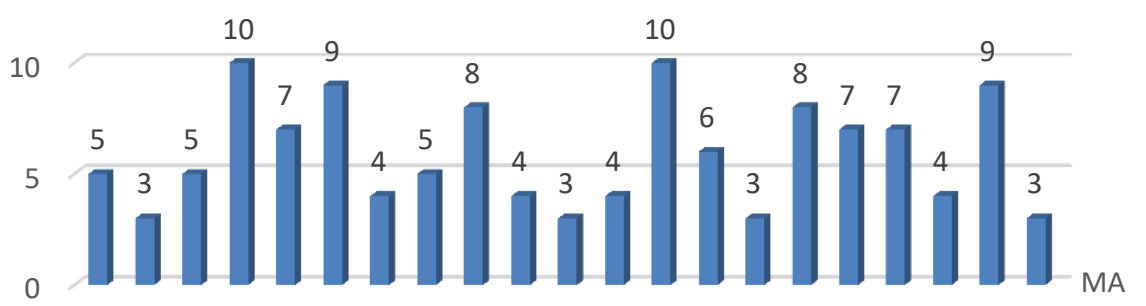

$\begin{array}{llllllllll}11 & 12 & 13 & 14 & 15 & 16 & 17 & 18 & 19 & \mid 10\end{array} \mid 11$ |12 |13 |14 |15 |16 |17 |18 |19 |20 |21

Figura 3. Frecuencia del hábito mental productivo de mantener la mente abierta.

En la figura 4 se observa que los informantes 13 y 18 fueron quienes lograron contener la impulsividad, se identifican 13 ideas con esta característica en su reflexión; en contraste con los informantes 11, 19 y 21 quienes contuvieron su impulsividad en su reflexión solo en 3 ocasiones. Se presenta un ejemplo de esta característica del informante 2. "Me dio la pauta para seguir los lineamientos establecidos y así evitar problemas por la revisión del documento por parte de gente externa” (I2, 2017). En la parte del comentario del informante 2, donde a la letra dice: "evitar problemas por la revisión del documento por parte de gente externa" se observa que el participante contiene su impulsividad porque reconoce que retrasar la decisión de enviar el documento hasta considerar que está completo. Lo que evidencia que procedió con reflexión y cautela al contener su impulsividad. La figura 4 muestra el concentrado de esta característica.

\section{Contener la Impulsividad (CAI)}

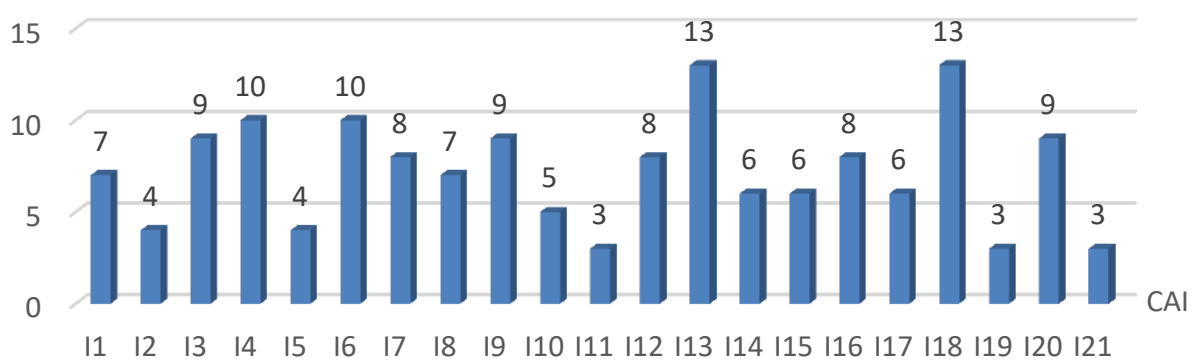

Figura 4. Frecuencia del hábito mental productivo de contener la impulsividad.

En la figura 5 se observa que el informante 4 fue quien logró asumir una postura cuando la situación lo ameritaba, con un mayor número de veces a diferencia de los demás informantes, esta característica se ubicó 11 veces en su reflexión; en contraste con los informantes 1 y 21, quienes asumieron una postura en su reflexión solo en 3 ocasiones. 
Se presenta un ejemplo de esa característica del informante 9. "Dentro de las dinámicas trabajadas fue muy interesante que al socializar los temas iniciales, surgieron nuevas ideas, además de temas afines y/o temas complementarios, aunque de inicio las temáticas de investigación parecieran ser diferentes" (I9, 2017). En este comentario escrito el informante 9 se observa que tomó una postura porque externó que aun cuando al inicio de las temáticas de investigación parecieran ser diferentes su postura fue seleccionar el mismo tema inicial. La figura 5 muestra el concentrado de frecuencias de esta característica.

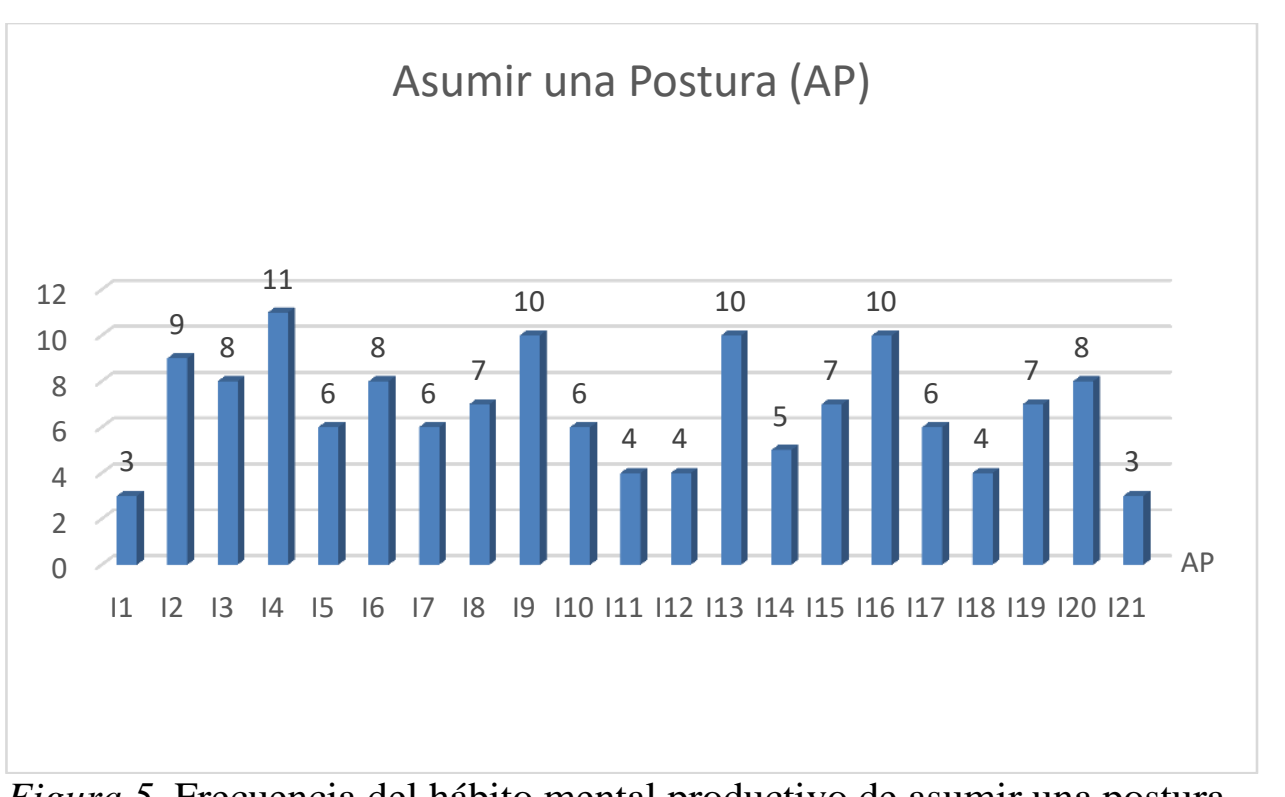

Figura 5. Frecuencia del hábito mental productivo de asumir una postura.

En la figura 6 se observa que los informantes 9 y 20 respondieron 8 veces de forma apropiada en su reflexión; en contraste con los informantes 2, 11, 12 y 19, quienes respondieron solo una vez de manera apropiada. Se presentan algunos ejemplos de esta característica de los informantes 8 y 9. "La discusión y participación de los diferentes grupos de profesores que se registraron en el taller fue muy importante debido a que enriquecieron las ideas particulares y las experiencias que se expusieron fueron por demás importantes, así como la valiosa intervención de la expositora del taller" (I8, 2017). "En la dinámica para generación de ideas al trabajar con las herramientas de apoyo, en nuestro equipo de seleccionamos un mapa conceptual. Lo destacable es que nos ayudó de una manera sencilla a organizar nuestras ideas y sobre todo a enlazar las áreas que teníamos inicialmente como áreas individuales, es decir, con pocos conceptos teníamos una idea más completa de la investigación y de sus alcances” (I9, 2017).

En los comentarios expresados por los informantes 8 y 9 se identifica que respondieron de manera apropiada a los sentimientos y al nivel de conocimientos de los demás, porque interactuaron con otras personas para compartir sus ideas, en las siguientes partes de los escritos "La discusión y participación de los diferentes grupos de profesores que se registraron en el taller fue muy importante" (I8, 2017) y "En la dinámica para generación de ideas al trabajar con las herramientas de apoyo, en nuestro equipo de seleccionamos un mapa conceptual. Lo destacable es que nos ayudó de una manera sencilla a organizar nuestras ideas" (I9, 2017), se evidencia que los informantes muestran respeto hacia los demás y logran una meta (borrador de un 
artículo en equipo) que depende de la colaboración y la cooperación de todos los integrantes del equipo. La figura 6 presenta el concentrado de frecuencias de esta característica.

\section{Responder de Manera Apropiada (RA)}

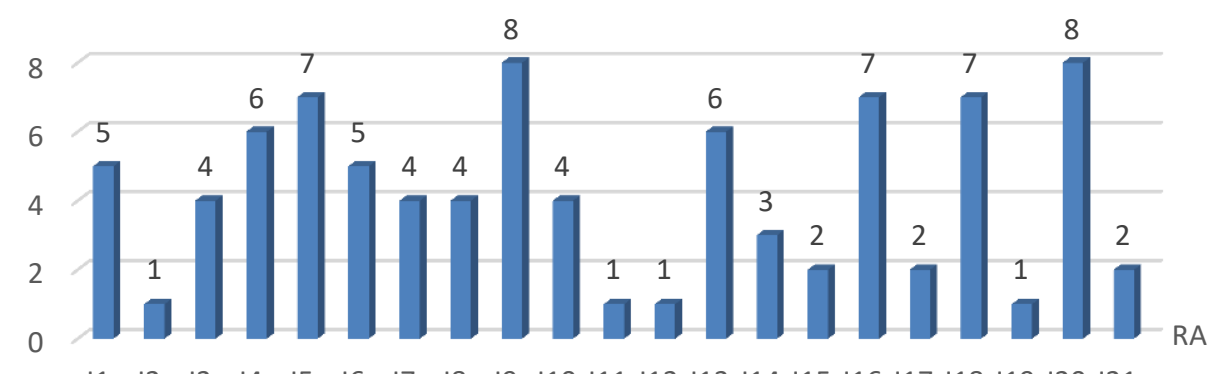

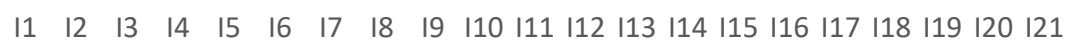

Figura 6. Frecuencia del hábito mental productivo de responder de manera apropiada.

Los comentarios expresados por los informantes 1 y 4 son claros porque la comunicación es nítida, escriben lo que desean decir, la información que presentan es concisa, no es confusa y es directa. La figura 2 presenta el concentrado de frecuencias de características de claridad. Donde se observa que los informantes 6 y 18 escriben con más claridad.

\section{Ser Claro y buscar la Claridad (CC)}

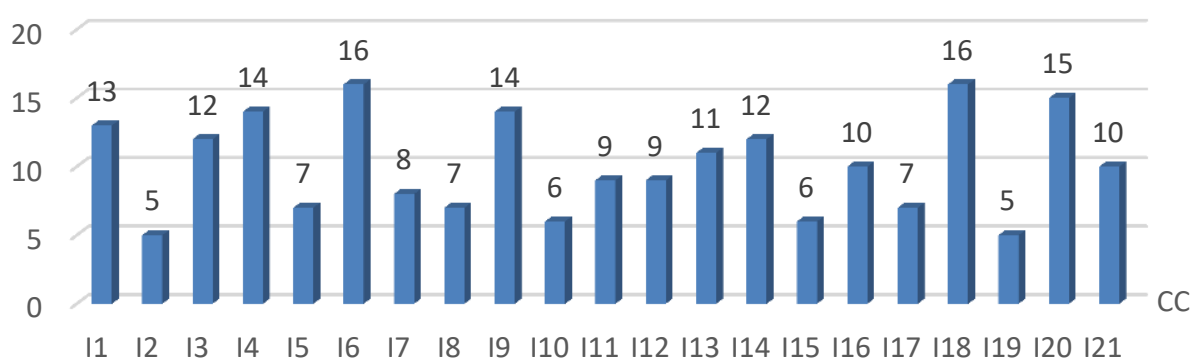

Figura 2. Frecuencia del hábito mental productivo de claridad.

En la figura 3 se observa que los informantes 4 y 13 fueron quienes lograron mantener la mente abierta, se ubican 10 ideas en su reflexión con esta característica; en contraste con el informante 2, quien mantuvo la mente abierta en su reflexión solo en 3 ocasiones. Se presentan algunos ejemplos de esta característica de los informantes 1 y 4. 
"aprendi de mis compañeros del curso ya que aportaron ideas y experiencias que enriquecieron mi conocimiento en torno a las vicisitudes a las que nos enfrentamos todo el tiempo los que realizamos investigación y queremos publicar correctamente y con calidad" (I1, 2017). Otro ejemplo, "En lo particular aprendí técnicas sencillas pero muy importantes para el desarrollo de una idea de investigación, particularmente la técnica de la estrella... me pareció muy práctica y el hecho de realizarla en el propio taller me permitió darme cuenta de otras formas de desarrollar un trabajo de investigación para su posterior publicación" (I4, 2017).

En los comentarios expresados por los informantes 1 y 4 se observa que tienen una mente abierta porque socializaron e interaccionaron son sus compañeros el I1 externo que aprendió de sus compañeros y el I4 aprendió la técnica de la estrella, en el diseño instruccional fue una actividad realizada en equipo, en las siguientes partes de los escritos de los mismos informantes "aportan ideas y experiencias que enriquecieron mi conocimiento" y "el hecho de realizarla en el propio taller me permitió darme cuenta de otras formas" se observa que los informantes escucharon perspectivas e ideas diferentes con el fin de mantener una mente abierta para entenderlas. La figura 3 muestra el concentrado de frecuencias de la característica Mente abierta.

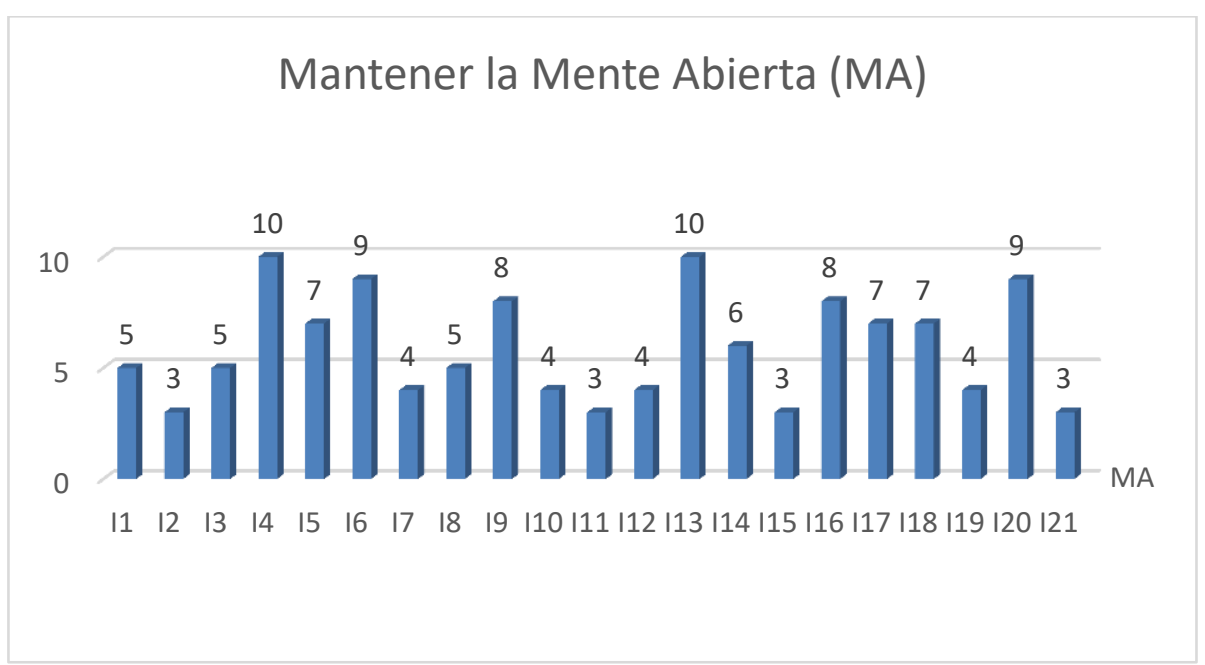

Figura 3. Frecuencia del hábito mental productivo de mantener la mente abierta.

En la figura 4 se observa que los informantes 13 y 18 fueron quienes lograron contener la impulsividad, se identifican 13 ideas con esta característica en su reflexión; en contraste con los informantes 11,19 y 21 quienes contuvieron su impulsividad en su reflexión solo en 3 ocasiones. Se presenta un ejemplo de esta característica del informante 2. "Me dio la pauta para seguir los lineamientos establecidos y así evitar problemas por la revisión del documento por parte de gente externa" (I2, 2017). En la parte del comentario del informante 2, donde a la letra dice: "evitar problemas por la revisión del documento por parte de gente externa" se observa que el participante contiene su impulsividad porque reconoce que retrasar la decisión de enviar el documento hasta considerar que está completo. Lo que evidencia que procedió con reflexión y cautela al contener su impulsividad. La figura 4 muestra el concentrado de esta característica. 


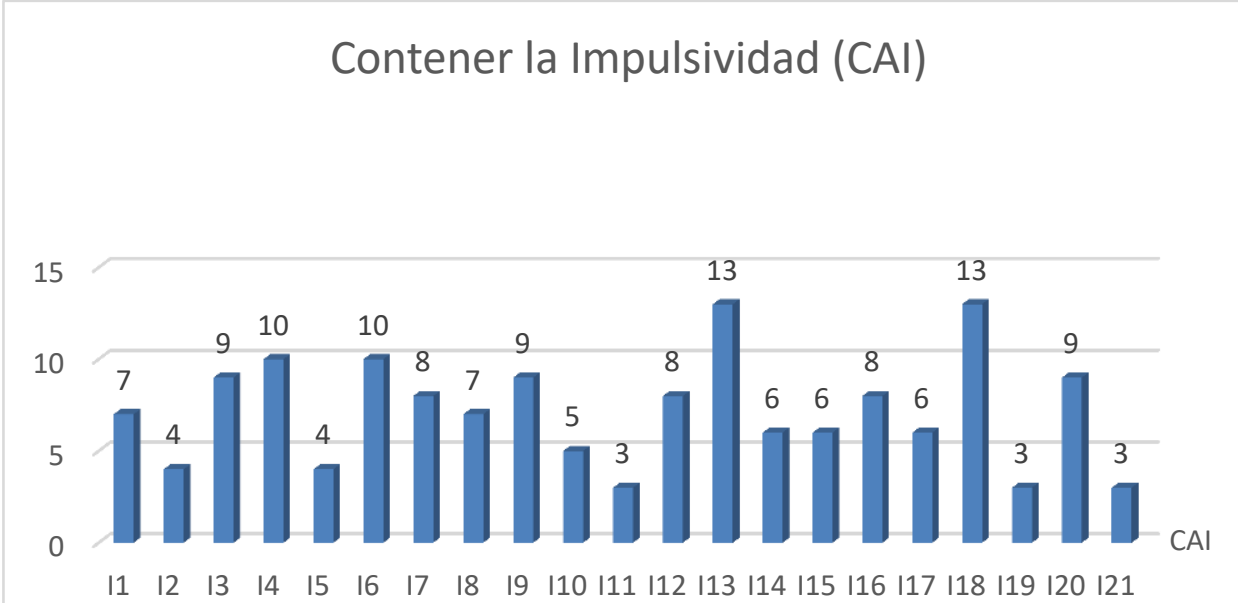

Figura 4. Frecuencia del hábito mental productivo de contener la impulsividad.

En la figura 5 se observa que el informante 4 fue quien logró asumir una postura cuando la situación lo ameritaba, con un mayor número de veces a diferencia de los demás informantes, esta característica se ubicó 11 veces en su reflexión; en contraste con los informantes 1 y 21, quienes asumieron una postura en su reflexión solo en 3 ocasiones.

Se presenta un ejemplo de esa característica del informante 9. "Dentro de las dinámicas trabajadas fue muy interesante que al socializar los temas iniciales, surgieron nuevas ideas, además de temas afines y/o temas complementarios, aunque de inicio las temáticas de investigación parecieran ser diferentes" (I9, 2017). En este comentario escrito el informante 9 se observa que tomó una postura porque externó que aun cuando al inicio de las temáticas de investigación parecieran ser diferentes su postura fue seleccionar el mismo tema inicial. La figura 5 muestra el concentrado de frecuencias de esta característica.

\section{Asumir una Postura (AP)}

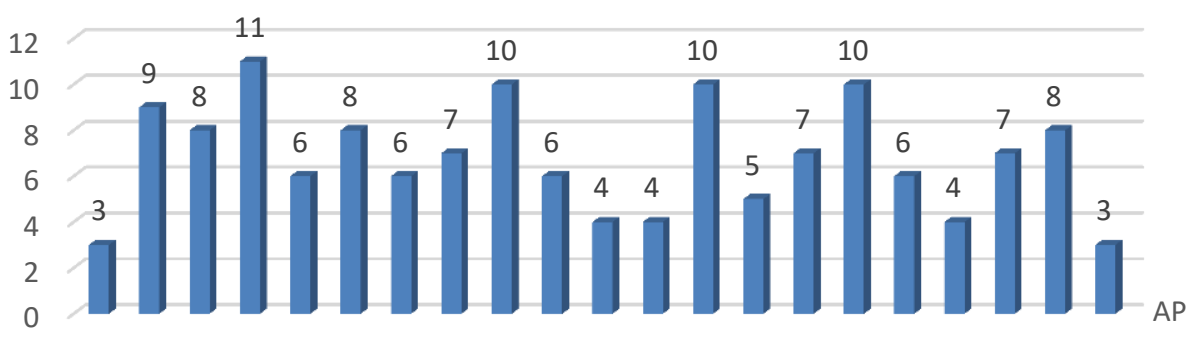

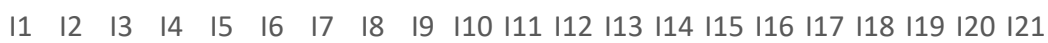

Figura 5. Frecuencia del hábito mental productivo de asumir una postura.

La metacognición en la profesionalización docente: el pensamiento crítico en un entorno mixto. Adriana Margarita Pacheco-Cortés y Elba Patricia Alatorre-Rojo. 
En la figura 6 se observa que los informantes 9 y 20 respondieron 8 veces de forma apropiada en su reflexión; en contraste con los informantes 2, 11, 12 y 19, quienes respondieron solo una vez de manera apropiada. Se presentan algunos ejemplos de esta característica de los informantes 8 y 9. "La discusión y participación de los diferentes grupos de profesores que se registraron en el taller fue muy importante debido a que enriquecieron las ideas particulares y las experiencias que se expusieron fueron por demás importantes, así como la valiosa intervención de la expositora del taller" (I8, 2017). "En la dinámica para generación de ideas al trabajar con las herramientas de apoyo, en nuestro equipo de seleccionamos un mapa conceptual. Lo destacable es que nos ayudó de una manera sencilla a organizar nuestras ideas y sobre todo a enlazar las áreas que teníamos inicialmente como áreas individuales, es decir, con pocos conceptos teníamos una idea más completa de la investigación y de sus alcances” (I9, 2017).

En los comentarios expresados por los informantes 8 y 9 se identifica que respondieron de manera apropiada a los sentimientos y al nivel de conocimientos de los demás, porque interactuaron con otras personas para compartir sus ideas, en las siguientes partes de los escritos "La discusión y participación de los diferentes grupos de profesores que se registraron en el taller fue muy importante" (I8, 2017) y "En la dinámica para generación de ideas al trabajar con las herramientas de apoyo, en nuestro equipo de seleccionamos un mapa conceptual. Lo destacable es que nos ayudó de una manera sencilla a organizar nuestras ideas" (I9, 2017), se evidencia que los informantes muestran respeto hacia los demás y logran una meta (borrador de un artículo en equipo) que depende de la colaboración y la cooperación de todos los integrantes del equipo. La figura 6 presenta el concentrado de frecuencias de esta característica.

\section{Responder de Manera Apropiada (RA)}

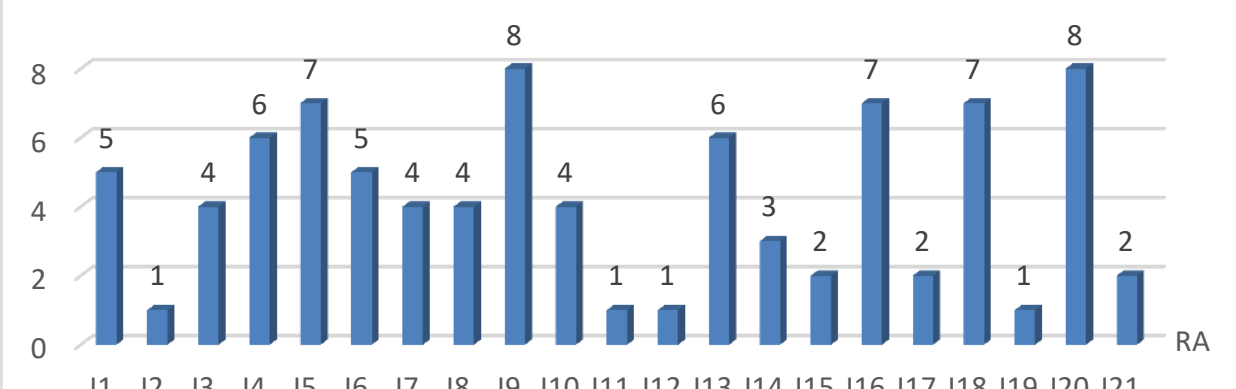

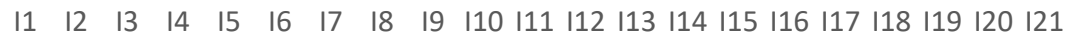

Figura 6. Frecuencia del hábito mental productivo de responder de manera apropiada.

\section{Análisis y discusión}

El objetivo de esta investigación fue identificar las características del pensamiento crítico en la redacción de un escrito sobre la reflexión metacognitiva de los aprendizajes logrados en un taller del PROFACAD y cómo los relacionan con su práctica docente cotidiana. Como los escritos fueron reflexiones sobre los aprendizajes, las actividades se 
consideraron como metacognitivas porque los docentes externaron sus pensamientos sobre su aprendizaje y sus procesos para aprender/conocer. La actividad contribuyó al desarrollo de la habilidad de los docentes para aplicar un proceso de reflexión metacognitivo al relacionar sus aprendizajes con su práctica docente.

Se evidenció que todos los informantes realizaron un análisis, una interpretación y una evaluación de los aprendizajes del taller porque lo evidenciaron en los escritos entregados. La mayoría posee las características del pensamiento crítico propuestas por Marzano y Pickering (2005): (a) ser preciso y buscar la precisión, (b) ser claro y buscar la claridad, (c) mantener la mente abierta, (d) contener la impulsividad, (e) asumir una postura y (f) responder de manera apropiada.

La característica del pensamiento crítico de mayor frecuencia fue "Ser preciso y buscar precisión". La de menor frecuencia fue "Responde de una manera apropiada a los sentimientos y al nivel de conocimientos de los demás”. Marzano y Pickering (2005) señalaron que es necesario que los participantes demuestren la capacidad para usar los hábitos mentales productivos de una manera consciente, que muestren qué entienden cuándo y por qué son necesarios los hábitos específicos.

Uno de los resultados sobre la característica de "Ser preciso y buscar precisión" se identificó en los comentarios de los informantes 1 (I1) y 4 (I4); son precisos porque especifican puntualmente, determinan a ejecutar algo, en las siguientes partes de los escritos "el proceso de construcción de conocimiento" (I1) y "el curso-taller totalmente funcional y aplicable" (I4) se evidencia que están estructurados con precisión.

Al respecto, Marzano y Pickering (2005) señalaron que buscar la precisión en la información que se recibe es reconocer que es responsabilidad del receptor de la información -tanto como del emisor- fijar y esperar altos estándares de precisión.

De lo anterior, se infiere que si en la precisión se fijan altos índices de ella, entonces en los procesos de escritura de un artículo, es responsabilidad del emisor fijar y esperar altos estándares en la redacción. Además que esta precisión permite a los escritores entender los efectos que el pensamiento crítico tiene sobre esos procesos de escritura.

Esos comentarios expresados por los informantes 1 y 4 son claros porque la comunicación es nítida. Escribieron lo que desearon decir, la información que presentaron es concisa, no es confusa y es directa.

Si los informantes escribieron lo que querían decir entonces la comunicación es clara y precisa tal como propusieron el hábito mental Ponce (2002), Costa y Kallick (1999). En los resultados de los informantes 2, 4, 5, 7, 8, 9, 10, 11, 12, 15, 17 y 20 las categorías de precisión y claridad son iguales, es decir, tienen la misma frecuencia, lo cual evidencia el 57\% de los informantes manejan la precisión vinculada con la claridad, el resto debe trabajar esta característica del pensamiento crítico.

Ponce (2002), Costa y Kallick (1999) integraron las características de "Ser preciso y buscar precisión" y "Ser claro y buscar claridad" en un solo hábito mental y lo propusieron como "Pensar y comunicarse con claridad y precisión" Con relación a este 
resultado se considera pertinente la modificación a las características del pensamiento crítico propuesta por estos autores.

\section{Conclusiones}

La metacognición es un constructo complejo tal como lo han señalado autores como Lai (2011) y Säälik (2016), por esa complejidad, algunos investigadores como Lai (2011) señalaron que los estudios se han centrado sólo en uno o algunos aspectos de la metacognición. La delimitación en la investigación que se realizó, fue centrarnos en los hábitos mentales productivos planteados por Costa y Kallick en Ponce (2002) y las características que plantean Marzano y Pickering (2005) para el pensamiento crítico en un grupo de profesores en formación.

Para Lai (2011) la evaluación de la metacognición es un desafío por varias razones: (1) la metacognición es un constructo complejo, que implica una serie de diferentes tipos de conocimientos y habilidades; (2) no es directamente observable; (3) puede confundirse en la práctica tanto con capacidad verbal como con capacidad de memoria de trabajo; Y (4) las medidas existentes tienden a ser estrechas en el enfoque y descontextualizadas del aprendizaje en la escuela. La evaluación de la metacognición que se realizó para el grupo de profesores de PROFACAD fue con un método observacional, el análisis de contenido.

Whitebread et al. (2009) declararon que, en la evaluación de la metacognición, los métodos observacionales tienen ventajas sobre los métodos de auto-reporte y de pensamiento en voz alta. Los enfoques observacionales registran los comportamientos reales de los informantes, lo que permitió considerar los comportamientos no verbales.

Además, las técnicas de observación pueden registrar procesos sociales que pueden ser importantes en el desarrollo de habilidades metacognitivas. En las observaciones realizadas en el análisis de la información recolectada en las reflexiones de la investigación de los profesores de PROFACAD se consideraron los comportamientos no verbales y los procesos sociales en el desarrollo de habilidades metacognitivas de esos profesores.

En este sentido, dentro de esta evaluación de metacognición, aun cuando en este reporte de investigación no se incluyeron el análisis de errores y la toma de decisiones, que forman parte del pensamiento crítico si se identificaron en los escritos de los docentes que siendo especialistas en un área de conocimiento, no son profesionales de la educación al no tener, de base, una formación docente. Si los docentes no tienen conocimiento y formación para el desarrollo del pensamiento crítico, como hábito mental que ayuda a la metacognición, no se puede tener la certeza de que los estén desarrollando en sus estudiantes.

Evaluar lo que los docentes en un curso mixto expresaron en una reflexión metacognitiva escrita y enviada a la plataforma Moodle, permitió ubicar características del pensamiento crítico en quienes desempeñan el rol de apoyo al aprendizaje, lo que da idea de la necesidad de formar a los profesionistas, inmersos en la docencia, en el desarrollo de hábitos mentales para que los utilicen y apoyen su desarrollo en sus estudiantes. 
Esas reflexiones individuales fueron (1) si lograron aprendizajes, (2) si fueron significativos y (3) cómo relacionaron esos aprendizajes con su práctica docente. Se trata de un tema socio-educativo que abre la discusión entre docentes e investigadores sobre el pensamiento crítico y la metacognición en un proceso de formación docente. Las argumentaciones que ofrecieron esos docentes en estas reflexiones resultan relevantes para este estudio, las experiencias evidenciaron sus puntos de vista diferentes, su subjetividad y lo más importante, las situaciones internas de aprendizaje que externaros en las reflexiones escritas por ellos mismos.

Presentación del artículo: 20 de diciembre de 2017 Fecha de aprobación: 13 de enero de 2018 Fecha de publicación: 31 de enero de 2018

Pacheco-Cortés, A.M., y Alatorre-Rojo, E.P. (2018). La metacognición en la profesionalización docente: el pensamiento crítico en un entorno mixto. RED. Revista de Educación a Distancia, 56. Consultado el (dd/mm/aaaa) en http://www.um.es/ead/red/56/pacheco_alatorre.pdf

\section{Financiación}

Esta investigación no ha recibido subvención específica de los organismos de financiación en los sectores públicos, comerciales o sin fines de lucro. El presente trabajo se inserta en el proyecto de investigación denominado "Metacognición y pensamiento crítico en profesores universitarios", en el Centro de Gestión del Conocimiento y del Aprendizaje en Ambientes Virtuales del Sistema de Universidad Virtual de la Universidad de Guadalajara (UdeG) en México.

\section{Referencias bibliográficas}

Campos, A. (2007). Pensamiento crítico. Técnicas para su desarrollo. Bogotá Colombia, Cooperativa Editorial Magisterio.

Carlós, L., \& Telmo, D. (s.f.). Análisis de contenido: su presencia y uso en las Ciencias Sociales. Recuperado de: http://www.fhumyar.unr.edu.ar/escuelas/3/materiales\% 20de\%20catedras/trabajo\%20de\%20campo/telmoyluis.htm

Flavell, J. H. (1976). Metacognitive aspects of problem solving. En L. B. Resnick (Ed.), The nature of intelligence (231-235). Hillsdale, N.J.: Erlbaum.

Gómez, M. (1999). Análisis de contenido cualitativo y cuantitativo: Definición, clasificación y metodología. Revista de Ciencias Humanas. 2. Recuperado de http://www.utp.edu.co/ chumanas/ 
Krippendorff, K. (1990). Metodología del análisis de contenido. Teoría y Práctica. Barcelona: Paidós.

Krüger, K. (2006). El Concepto de Sociedad del Conocimiento. Revista bibliográfica de geografía y ciencias sociales. (Serie documental de Geo Crítica).Recuperado de http://www.ub.edu/geocrit/b3w-683.htm

Lai, E. R. (2011). Metacognition: A literature review. Always learning: Pearson research report.

López, F. (2002). El análisis de contenido como método de investigación. Revista de Educación, 4, 167-179. Recuperado de http://uhu.es/publicaciones/ojs/index. php/xxi/article/viewFile/610/932

Marzano, R, J. \& Pickering, D. J. (2005) Dimensiones del aprendizaje. Manual para el maestro. $2^{\mathrm{a}}$ ed. ITESO, México.

Ponce, M. (2002) Reseña de Los Hábitos de la Mente de Costa, A. \& Kallick, B. Revista del Centro de Investigación. Universidad La Salle 5, 103-105. Recuperado de http://www.redalyc.org/pdf/342/34251811.pdf

Säälik (2016), Ü. (2016). Reading literacy performance: Metacognitive learning strategies matter, schools have effect on student outcomes. Recuperado de http://193.40.4.3/bitstream/handle/10062/51602/saalik_ylle.pdf?sequence=1\&is Allowed=y

Universidad de Guadalajara, Centro Universitario de la CIÉNEGA (2016). Informe de Actividades 2015-2016 del Centro Universitario de la CUCIÉNEGA. María Felicitas Parga Jiménez. Rectora. Recuperado de http://cuci.udg.mx/sites/default/files/adjuntos/discurso_de_la_mtra._mariea_felie citas_parga_jimeenez_con_motivo_del_informe_de_actividades_del_cucieenega _2015_2016.pdf

Universidad de Guadalajara, Programa de Formación, Actualización y Capacitación Docente (2017a). Presentación. Recuperado de http://www.cga.udg.mx/?q=formacion-docente/presentacion

Universidad de Guadalajara, Programa de Formación, Actualización y Capacitación Docente (2017b). Estructura. Recuperado de http://www.cga.udg.mx/?q=formacion-docente/estructura

Whitebread, D., Coltman, P., Pasternak, D. P., Sangster, C., Grau, V., Bingham, S., Al Miqdad, Q., \& Demetriou, D. (2009). The development of two observational tools for assessing metacognition and self-regulated learning in young children. Metacognition and Learning, 4(1), 63-85. 